Thus, to mention one, in spite of his claim to have chosen the commonest reactions, one wonders how many people use, still less have heard of, the "Lobry De BruynAlberda Van Ekenstein Transformation".

Whether it is a worthwhile project to bring together a selection of named reactions is debatable. In so far as each chapter has a bibliography appended to it, the book does serve some purpose. But a bit of reaction conditions plus a smattering of mechanism does not add up to a satisfactory whole. Almost half the reactions mentioned have been dealt with more fully in a well established series which is the source that postgraduates and others will consult. As for the average undergraduate of today, it is doubtful if he needs to know or gets taught the names of most of the remainder.

The present compilation seems at least as good as one or two others already in existence. The book is nicely produced and is cheap, but I doubt if it will achieve a wide readership.

E. J. FORBES

\section{SCOPE OF SUPERCONDUCTIVITY}

\section{A Guide to Superconductivity}

Edited by David Fishlock. Pp. $\mathrm{x}+150$. (Macdonald: London; American Elsevier: New York, November 1969.) 45s; 87 .

THIs book is a collection of contributions from individual authors covering eight aspects of superconductivity. The first, by N. P. Allen, on the origins of superconductivity, lists the superconducting elements, describes superconducting phenomena and concludes with a brief discourse on the microseopic theory. It is followed by J. A. Catterall's article on high field materials, which discusses commercial materials, stability and a.c. losses. The lines along which improvements in critical current, field and temperature, may be expected are indicated.

J. E. C. Williams's contribution on small magnet technology is the best of the eight, because its subject is the most well defined and least speculative. It is largely concerned with the behaviour of different materials when wound into small coils. It is complemented by P. F. Smith's article on the technology of large magnets. Large magnets are described and their design problems are discussed.

Superconductors in motion, by A. D. Appleton, is, understandably, devoted to the author's own homopolar supereonducting motor, with brief mention of other schemes for rotating superconducting machinery. W. T. Norris describes the possible future for superconductors in power transmission. Design for a.c. cables, the possibility of d.c. transmission, superconducting transformers, rectifiers and storage systems are explored but are concluded to be not economic.

The cryogenic computer is resurrected by P. A. Walker, and is shown to have some advantages, particularly that of high density memory storage at low cost. The most unhappy contribution is that of C. Laverick on trends in superconductivity. Much of it merely repeats some of what has been said in previous chapters. The only new ground covered concerns devices using the Josephson effect, and these are very inadequately described.

The book as a whole is disappointing in that every discussion stops short of being really interesting to one who has some knowledge of superconductivity. The book is of little value to persons familiar with the subject, but may be recommended to non-experts for a quick and painless indication of the scope of superconductivity and its possible applications.

Laverick's brief mention of economic analysis tempts one to consider the economies of this book. Its price does seem too high for 150 pages of non-specialist information published and printed in Great Britain.

David Dew-Hughes

\section{TRADITIONAL QUANTA}

\section{Quantum Mechanics}

By A. Rubinowicz. Pp. viii + 584. (Elsevier: Amsterdam, London and New York; PWN-Polish Scientific: Warszawa, 1968.) 150s.

THIs is a large textbook, written in a painstaking and leisurely idiom, on the more traditional aspects of quantum mechanics. It is explicitly designed for students following courses in the subject and endeavours to clear their path by the provision of appendices on classical mechanics and other more mathematical matters. The book therefore constitutes another addition to the recent veritable flood of texts on quantum mechanics. It is comprehensive and therefore invites comparison with the treatises of Schiff, Messiah or Gottfried. Like these books, the book under review is in the main restricted to the non-relativistic part of the subject and the Dirac equation and the quantized electromagnetic field make their appearance in the last two chapters. One is struck very forcibly, however, by the old fashioned approach, which reminds one of Sommerfeld's pre-war texts. This applies not only to the symbolic conventions. Professor Rubinowicz has of course an assured status in the subject, although he will be more readily romembered for his contribution to diffraction theory than his elucidation of optical quadrupole radiation. Internal evidence, however, suggests that his book was largely compiled in pre-war days and kept up to date by some piecemeal additions of more recent developments.

As far as the English-speaking market is concerned, there is now no lack of authoritative texts on the basic aspects of quantum mechanics, all written so as to facilitate the transition into some or other more specialized field. What is still urgently required are books on what might be called "advanced quantum mechanics" which bring the student in touch with the enormous number of recent developments, some formal, such as Green's functions and others conceptual, such as macroscopic aspects of Planck's quantum of action, and do so in a way which avoids premature specialization. Very recently, Professor Ziman has made a most promising start in this direction (see his book, Elements of Advanced Quantum Theory, Cambridge University Press).

Introductory and shorter teaching books with very specific aims, such as quantum mechanics for chemists or for students of applied mathematics, presumably have played, and will continue to play, their part. Unfortunately, Rubinowicz's book does not fit very well into either group, notwithstanding that it is a perfectly competent production. It will find its way into libraries, but I cannot see many teachers recommending it a "must" for the serious student of quantum mechanies. S. ZIENAU

\section{Appointments}

Mr E. E. Smith has been appointed acting director of the MRC Radiological Protection Service, following the retirement of $\mathrm{Mr}$ W. Binks. Mr Smith has been deputy director of the service since 1955 .

Professor V. A. Altekar has been appointed director of the National Metallurgical Laboratory, CSIR, Jamshedpur.

\section{Announcements}

The British Association for the Advancement of Science is entitled to table space and the use of research equipment and other material at the Biological Stations at Plymouth and Windermere and at the Naples Zoological Station. Although the time available at Naples is limited to one month during the twelve from July to the following June, there is no limit at Plymouth or 